\title{
Utilising Latent Data in Smart Buildings: A Process Model to Collect, Analyse and Make Building Data Accessible for Smart Industries
}

\author{
Zohreh Pourzolfaghar \\ Dublin City University, School of Computing \\ Dublin, Ireland \\ Zohreh.pourzolfaghar@dcu.ie
}

\author{
Markus Helfert \\ Dublin City University, School of Computing \\ Dublin, Ireland \\ Markus.helfert@dcu.ie
}

\begin{abstract}
Smart buildings are embedded with large amounts of latent data from different sources, e.g. IoT devices, sensors, and the like. Integration of this latent data with the buildings information can highly impact efficiency of the services provided by various industries, e.g. facility management companies, utility companies, smart commerce, and so forth. To manage buildings information, diverse technologies such as Building Information Modelling (BIM) technology have been developed and changed the traditional approaches. Notwithstanding a plethora of research in this area, potential users of this information, such as facility management companies, are still unable to fully benefit from the building information. This is due to the fact that various information and data have been heterogeneously scattered across various sources. To overcome this challenge, this research follows the design science approach to propose a process model to enable facility management industry to access the integration of buildings information with live data. The presented process model is introduced thoroughly by explaining the required steps to collect and integrate and preserve the integrated information and data. The evaluation of the process model was undertaken via the employment of a focus group session with the construction professionals, the IoT experts, and the data analysts. Also, this paper elaborates on two industrial use-cases to demonstrate how having access to the building information effectively affects the other industries. The outcome of this research provides an open access to the integration of building information and live data for diverse range of users.
\end{abstract}

Keywords - building information management, data capture, IOT devices, sensors, building Information Modelling (BIM)

\section{INTRODUCTION}

The smart buildings information is a valuable asset which can be utilised by various types of stakeholders in the smart cities, (e.g. by city councils for urban and infrastructure planning, maintenance/facility management companies to speed up their services and utility companies to estimate energy consumption). Smart building describes "a suite of technologies used to make the design, construction, and operation of buildings more efficient [28]. To enable smart buildings, [29] believed that a wider range of information should be available from a broader range of sources. The buildings information is generated during various stages of buildings life cycle. The first stage of buildings information creation is the design phase. This information is mostly related to the buildings specifications, spaces, heating and cooling systems and their specification and so on. Numerous researchers described various advantages gained from such information. For instance, [6] stated that it is exceedingly important to have the capability of quickly and reliably estimating the buildings' energy consumption, especially for public authorities and institutions that own and manage large building stocks. As Asadi [2] explained, estimating and predicting the buildings energy consumption depend on multiple variables like building characteristics, the energy systems characteristics. The operation phase is another stage of building life cycle in which new information is created. In this phase, the smart technologies, devices and sensors produce live data which can be utilized for the environmental monitoring applications [23] or for the combinational usage of different context data from different sources [8]. Likewise, combination of the live data with building information can provide priceless information for various potential users. For instance, live data on energy consumption for a building can be compared with the energy consumption estimation from the design phase. The results of this comparison can be utilized to promote energy saving behavior.

Despite of importance of this combination, many researchers reported challenges to take advantage from this combination. Some of these challenges are related to the vast complexity and volume of the data and information generated during the buildings' life cycle [14], fewer advances in the information management methodologies and fragmented models in the construction industry [17], [21].

Moreover, buildings information is scattered across the separated data storages and in heterogeneous formats. As [1] proclaimed, these issues contribute to some other key challenges in terms of the manual driven process to utilise the buildings information, lack of proper quality control procedures, and obsoleteness of the information.

With regard to the abovementioned challenges, this research proposes a process model with the aim of integrating the building information with the live data. In the subsequent parts of this paper, first we review some related research work in the building information management field. Then, a process 
model is introduced as the proposed solution. The evaluation section includes four sub-sections to provide more details on the evaluation steps, including the focus group session, exploring the two use-cases, and discussion on the results.

\section{RELATED RESEARCH WORKS}

During the last ten years, the Building Information Modelling (BIM) technologies have become more common to manage the buildings information. However, these technologies confront large number of challenges, e.g. updated data for the as-built BIM models [4], the pertinent semantic format for the maintenance stage [22], unsystematic use of the building information on the virtual models [16], the related procedures [5], the established standards [10], and the computerised facility management system integration [3].

As such some researchers reported challenges facing the maintenance stage to benefit from combination of building information. For instance, [18] reported several corresponding obstacles in terms of availability the required data for maintenance stage and t usability of the stored data format. As such [26] and [22] identified challenges relate to interoperability, interfaces with other systems, integration of wired and wireless sensor networks to enhance the live data collection during the construction phase, and controlling the access to the project information. Also, [15] proclaimed that the building maintenance requires a comprehensive information system that captures/retrieves the information about the building maintenance components and all their related building components. In this regard, they proposed an integrated information/knowledge system. However, this system was limited to capturing and retrieving the data during the maintenance phase.

The data integration was defined by [7] as: "the combination of data from different sources with unified access to the data for its users". Apparently, many researchers proposed methods and models to integrate the building information with the live data to facilitate the maintenance of the buildings. However, inadequate data integration is a current challenge faced by the building information models. According to [18] this challenge stems from differences in the data syntax, the schema, or the semantics. With regard to the studied literature, integration of information and data has been recognized a challenge. To tackle this challenge, this research aims to present a process model to collect, analyse, and integrate the building information with the live data captured from various IoT and smart devices and sensors.

\section{RESEARCH APPROACH}

This paper follows [19] the design science research approach to define the problem in terms of unavailability of a combination of the building information with the live data. To define the problem, related literature has been reviewed in the area of the technologies to manage the building information, e.g. the BIM. To support the problem in practice, the authors conducted meetings and workshops with the facility management teams as the potential users of this combination. Based on the evidences from the literature review and workshops with practitioners, the problem was defined as the inability to take advantage from the combination of buildings information with the live data. Therefore, this research proposed a process model to extract the buildings information and the live data from heterogeneous sources, then combine and store them in an open access storage. For the conceptual evaluation of the presented model, this study followed [25] to conduct a focus group discussion session. The focus group session passed through eight steps procedure [24], with the practitioners from the construction industry, the IOT experts and the data analysts. The results of evaluation provide evidences on relevancy of the proposed process model for the explored field.

\section{Process Model For BUILding INFORMATION AND LiVE DATA INTEGRATION}

Buildings information is known as a priceless resource for various smart industries. For instance, utility companies can utilise building information to estimate energy consumption and promote energy saving [20]. For this purpose, they need the cumulative information of electrical devices, while detailed buildings information may not be accessible. Similarly, other industries such as retailers can predict and manage market demands with regard to the technical specification for building components and materials [20]. However, building information is not openly available for these typical potential industry users. To provide such an ability, the initial overall idea to integrate building information with live data, as well as making buildings information accessible for all potential users, is presented in Fig 1. 


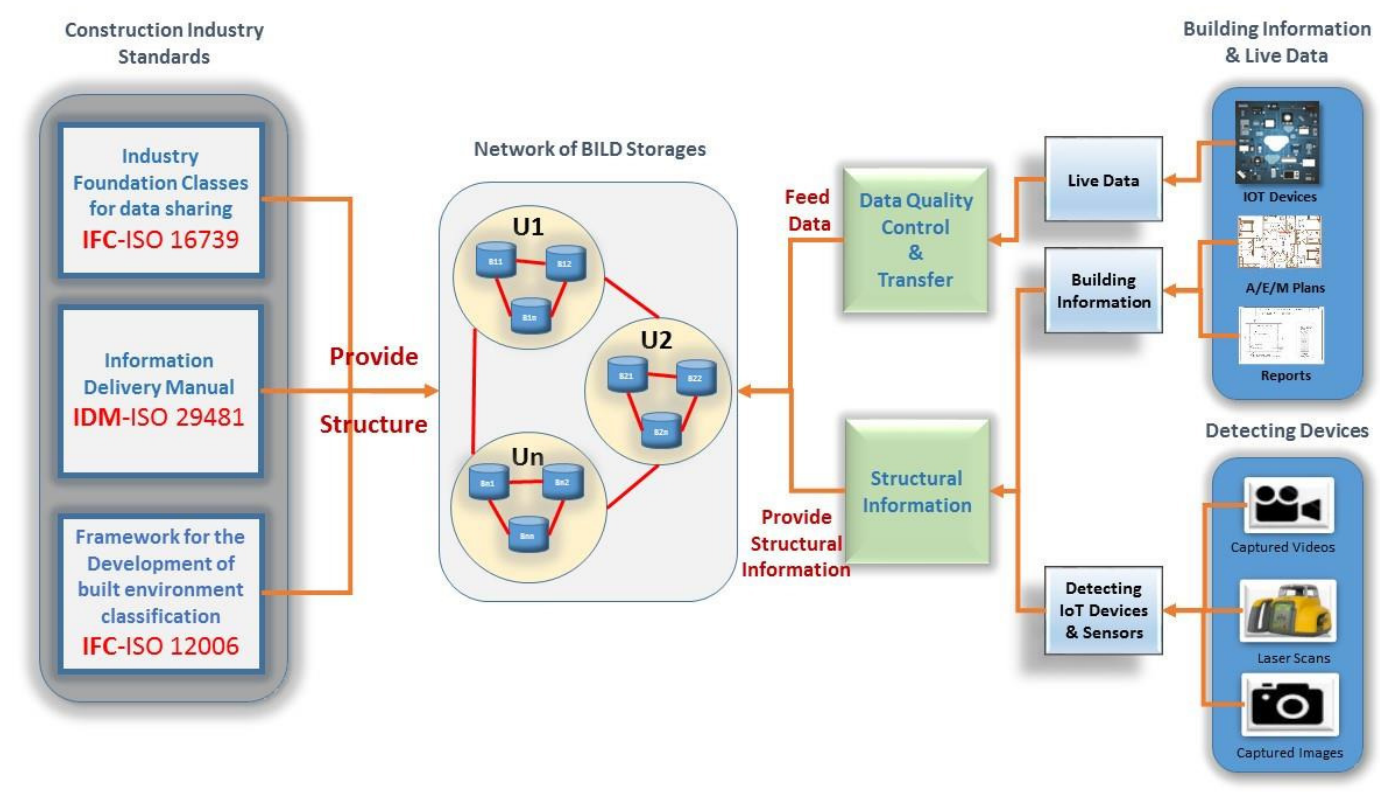

Fig. 1. The overall view of the Process Model

According to the diagram in Fig 1, buildings information and live data are extracted from various sources. The information and data are utilised for two different purposes, including: to define the structure of the storage; and to feed into the storage. The information and live data will feed into the storage after passing the quality control phase. Referring to the left side of the diagram, the existing construction industry standards (e.g. ISO 12006) for the information exchange should be considered to construct the storage. In the middle side, the network of BILD (Building Information \& Live Data) storages is presented. Any storage (e.g. B11) is for one building in an urban area (e.g. U1). Also all the storages are connected to each other.

Establishing on this overall view, this study proposes a process model to capture the data from various source and integrate them into a Building Information and Live Data (BILD) open storage. Consequently, four phases have been defined for the proposed process model. In the following subsections, the above mentioned phases of the process model are described thoroughly.

\section{A. Structuring BILD Open Storage}

The first phase of the proposed process model is structuring the open storage in which integrated and qualified building information and live data are stored. The open storages structure should comply with the construction industry standards, (i.e. ISO 16739, ISO 12006, ISO 29481). To develop such an open storage, the first phase of the process model comprises the following steps. The first step is exploring Building Information Modelling (BIM) standards, (which are the European standards for the construction industry). Based on these standards, all the data should follow the corresponding rules. Based on the explored standards, some structural and semantical requirements are specified. Regarding these requirements, an initial version of the open storage structure is defined. Another important requirement for this phase is defining and standardising the coding system for building spaces. Later, the assigned codes are used to link the collected live data from various sources to the buildings information. The presented process for this phase is shown in Fig. 2.

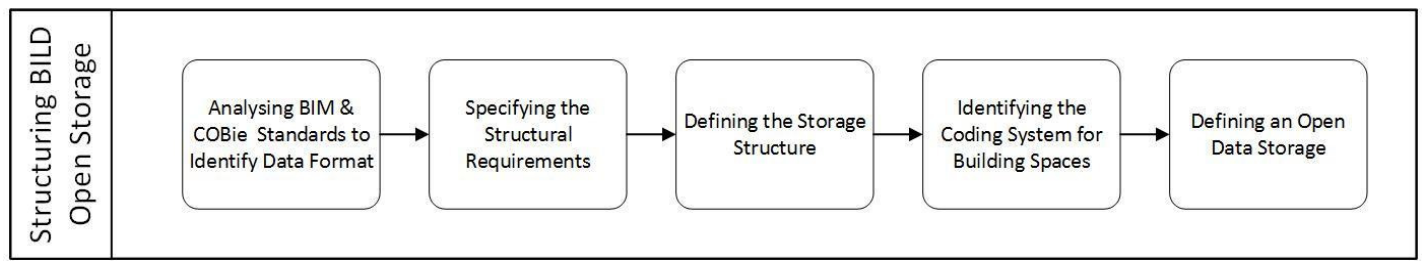

Fig. 2. The process of structuring BILD open storage

Structuring the BILD storage will be completed after accomplishing the second and third phases. This is due to the fact that the required fields to preserve the information and collected data are specified through the later steps.

\section{B. Multi-sources Building Information Capturing}

In this section the required steps to capture the buildings information from various sources (e.g. building plans, reports, IOT devices, sensors, etc.) are explained. To this goal, two different sub-processes are proposed in this section. The first 
process is to digitalise building information from architectural/mechanical/electrical plans as well as project reports. Building plans contains essential information about building spaces and their associated technical specification. Likewise, project reports comprise useful information on mechanical/electrical/structural aspects, e.g. building energy consumption. As the first step for this process, all this information is required to be digitalised. Then, the next step is using a coding system (defined in 4.1) to assign unique code to the building spaces. Later, there will be a need to provide a link between the digitalised building information from plans and from the project reports. This information is stored in the structured data storage in section 4.1. The defined process for this stage is shown in Fig. 3.

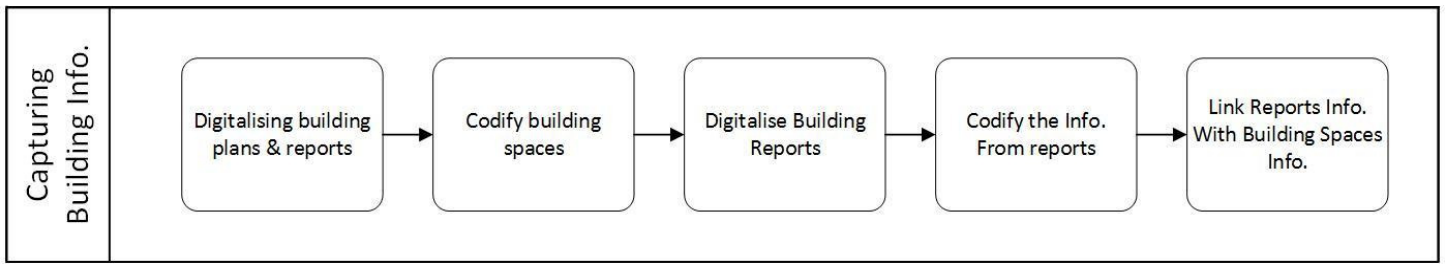

Fig. 3. The process of capturing building information from plans ad reports

The second process for this stage is detecting all the IOT devices and sensors installed in the building spaces. This process is to update the information about the new installed devices in building space. To do so, all these devices are detected using laser scans, captured images and video records.
The outcome of the detecting devices is in the form of point cloud data and they need to be converted into the objects. Moreover, some additional information e.g. coordination and location are utilised to link this information to the previous building information. The second process is presented in Fig. 4.

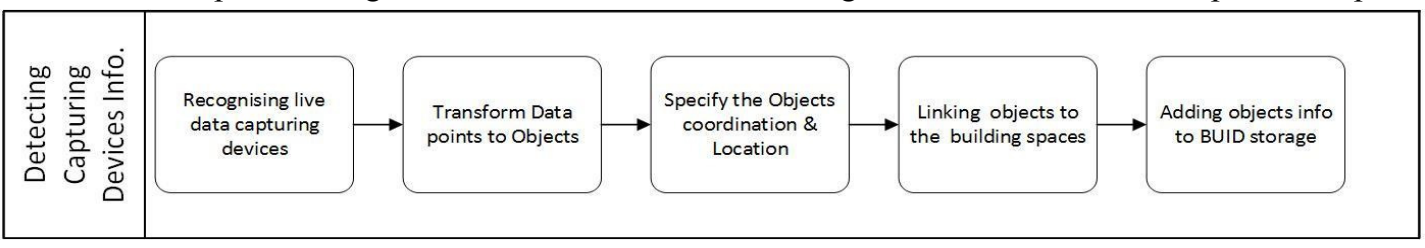

Fig. 4. The process of detectind IoT devices and sensors information

During this phase, some structural information is also provided to complete the structure of the data storage in phase 4.1. The iterative process of feeding live data into the BILD storage is presented later, in section D.

\section{Establishing a BILD Storages Network}

By providing a network of data storages for the buildings, an opportunity is arising to use integration of buildings information with live data for the urban planning purpose in smart cities (e.g. for infrastructure planning and waste water management based on energy consumption in an urban area).
To establish such a network, the required steps are explained as follows. In the first step of this process, locational information should be defined for the buildings. T Then, a codifying system should be defined to develop and assign a unique code to every building in an urban area in the city. This unique code is the reference number for each building. In this regard, all the buildings in the urban areas could be referenced with their unique code. Finally, the required field for all the above mentioned information in this phase should be added to the storage structure. The proposed process for this section is presented in Fig. 5.

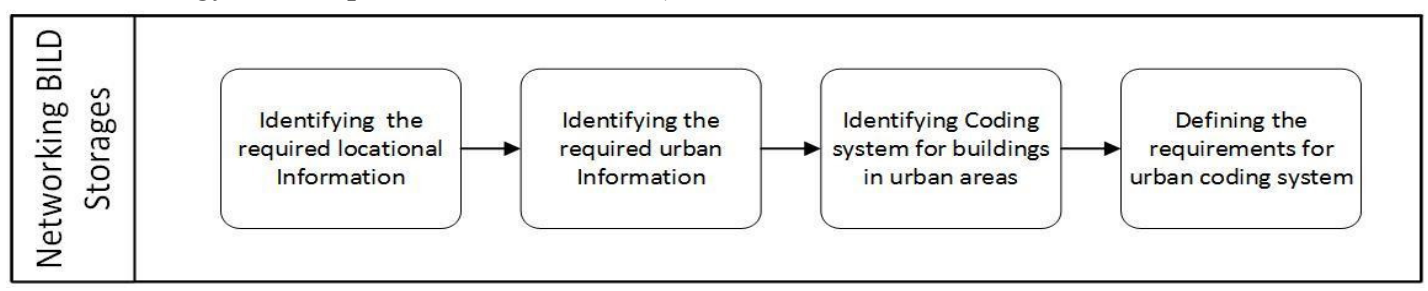

Fig. 5. The process building network of BILD storages

\section{Multi-sources Live Data Capturing}

The last phase of the proposed process model is transferring the qualified live data to the BILD storage. As the first step of this process, the live data is captured from the detected devices and sensor. The captured data from IoT and smart devices are stored in the database associated with their software. In this condition, there is a need to define an interface to obtain and transfer this data to the BILD storage. Referring to the second phase (i.e. 4.2), some fields have been defined to store the live data for the installed devices in the building spaces. Therefore, the capture data can be transferred to their related fields in the BILD storage. However, before this step there is a need to ensure about the quality of the captured data. In case of passing the quality control step, data is ready to be transferred to BILD storage. This process is shown in Fig. 6. 


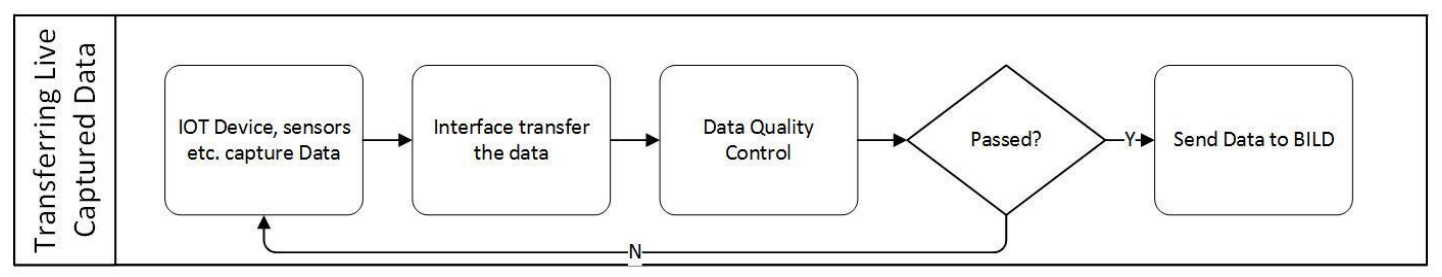

Fig. 6. The Qualifying and Transferring the live data to BILD storage

Indeed, this is the only iterative phase in the whole process model. This phase is responsible to provide the most updated data on the status of the installed devices in building spaces.

The abovementioned phases have been defined to collect, qualify, integrate and store building information and live data in an open storage. This storage will be accessible by all industries. The relations between these four phases are shown in Fig 7.

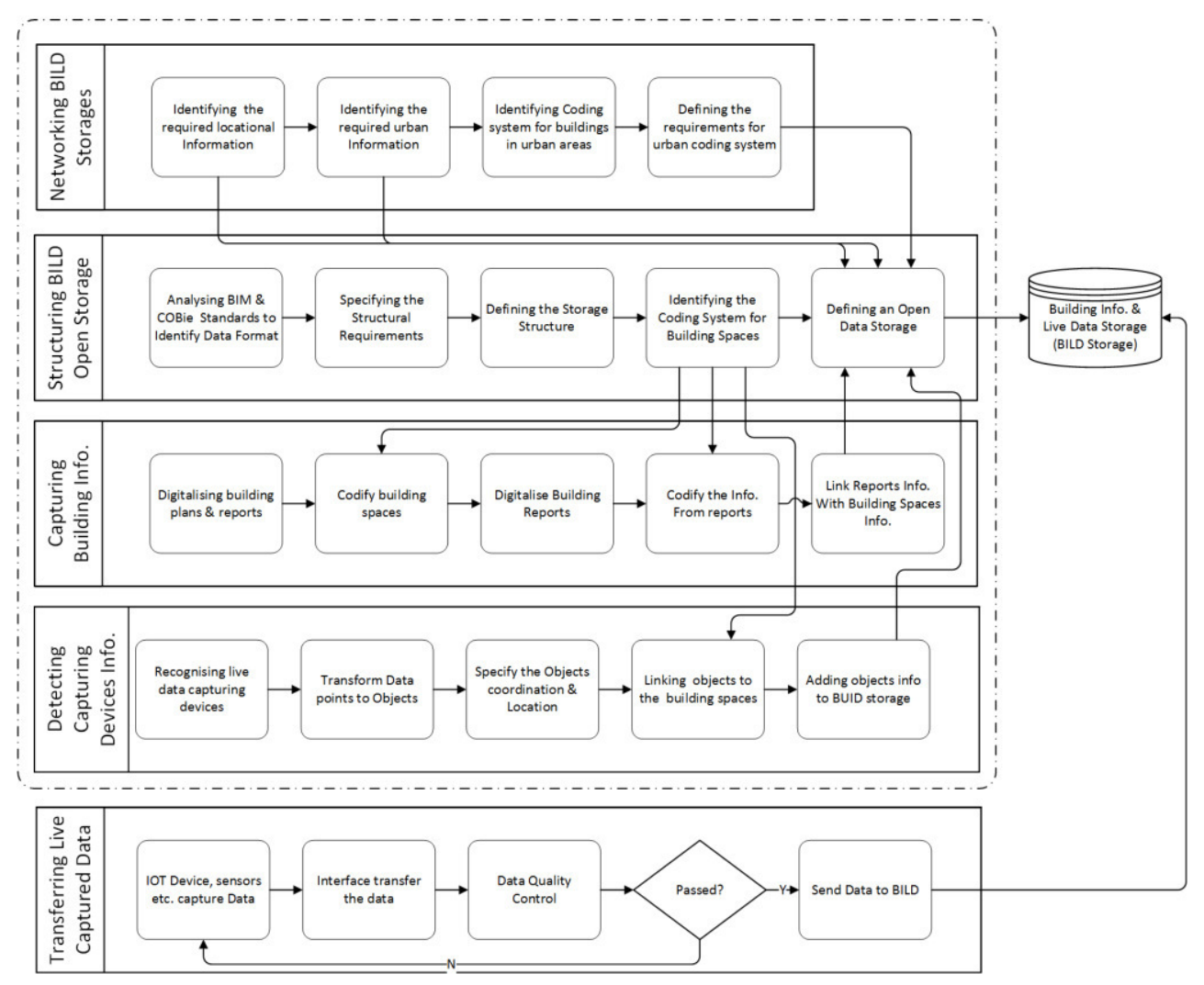

Fig. 7. The overall process model and relations between sub-processes

Based on the above process model, the defined subprocesses for four phases are interacting to build up the structure, as well as feeding the information into the BILD storage. The first four sub-processes in the process model are happening once (to construct the BILD storage structure), while the last phase is the iterative sub-process which continuously feed live data into the storage. Indeed, this phase is responsible to update the installed devices status. The proposed process model has been demonstrated to the experts in construction field, IOT devices and sensors for validation purpose. In the next section, more details are provided on the validation of the presented process model.

\section{VALIDATION}

For evaluation purpose of the presented process model, this research follows [25] ex-ante evaluation approach. To do this, first a focus group discussion was conducted for conceptual evaluation of the process model in terms of relevancy of the process model to the challenges in building information area. Later, two different use-cases are explained as the evidences to prove that this information are current in this field. In the following three sub-sections more details are provided on focus group discussion and two use-cases. Later, in the fourth subsection, a discussion is conducted on two evaluation aspects, i.e. relevancy and if the information is current. 


\section{A. Focus Group Discussion with Professionals}

According to procedure stated in [24], to apply focus groups in in the design science context, some steps are needed to be considered. The sequence of these steps are: 1) formulating the problem; 2) identifying sample frame; 3) identifying a moderator; 4) developing and pre-test a questioning route; 5) recruit participants; 6) conduct focus group; 7) analyse and interpret data; and 8) report the results. Based on these requirements, the question for the focus group session defined as: "whether the proposed model is relevant to the current challenges, (information and data integration), to manage building information'. The focus group attendees were six professional in the areas of construction industry, IOT and data analysis. This focus group session was conducted with the aim of providing some evidences from participants on how good this process model may fit into its defined goals. The main two goals of the process model are: 1) integration of building information and captured data; and 2) storing this information in an open access storage consistent with construction industry standards. The main objective for this session was getting a consensus on to how extend this process model may achieve its defined goals. Therefore, we invited two participants for each of three different areas in the process model, i.e. construction practitioners, IOT experts, data analysts. The moderator of the session was the main author of this paper who has a background in construction industry. For developing and pre-testing the questions, we first defined questioning route. For this purpose, this research followed [12] to conduct a conceptual evaluation. Then, we interviewed two invited practitioners and revised the questions based on their expertise. In the following two sub-sections two usecases of using building information are described as the evidences for usefulness of building information to other smart industries. Then, in sub-section 5.4 the results of focus group session and two use-cases are discussed altogether.

\section{B. Building Information and maintenance}

As [9] believed, the proliferation of advanced computerisation throughout industry has revolutionised the way that buildings are designed, constructed, operated and maintained. According to [15] one of the key challenges in building projects is the need to have sufficient information on products ready available for any maintenance operation. Also [16] believed that maintenance information of products installed into buildings should be available for maintenance stage. Likewise [16] stressed that detailed product data might be needed to respond to the demands from authorities or users to track the used products. Apparently, there is a high demand for integration of building information with live data from IoT and smart devices in buildings. Therefore, the proposed process model by this study can be a solution for the recognised challenges for maintenance phase of buildings.

\section{Building Information and Smart Energy}

Regarding the increased efforts for energy saving and energy cost reduction, utility companies attempt to find new ways to promote more effective ways of energy usage. In this regard, [6] emphasised on the importance of the capability to reliably estimate the buildings' energy consumption. For this purpose, many researchers utilised machine learning and data mining [27], or regression models [11] to predict and estimate building energy consumption. Some other researches e.g. [13] and [2] stressed that estimation of building energy consumption highly depends on building information. While many researchers proposed methods to estimate and calculate energy consumption, there are valuable resources to provide this information. The energy consumption for buildings are estimated during early design phase of buildings. As such, energy consumption for buildings are measured and calculated by IoT and smart device. Combination of this information can provide responses to many concerns, e.g. comparing the energy consumption with initial estimation to promote energy saving behavior.

\section{Discussion on Focus Group Results and Use-Cases}

During the focus group session, four different questions related to four phases of the proposed process model were discussed. According to the results, all the participants believed that different phases of the process model are relevant and necessary for data integration. Also they all stressed that this information is sufficiently current in their area. For instance, IOT experts stated that this is a new demand from their customers' side to have a list of IOT devices installed in the buildings and they are looking for a solution to respond to this need. Similarly, construction experts believed that the integration of live data with building information is an essential issue in this area. Therefore, they strongly believed that presented process model has the ability to address data integration issues. As a result of this evaluation session, all the participants believed that this process model is an appropriate and exact approach to respond the current demands in the construction industry. From the other side, two explored usecases realised that other smart industries may benefit the integrated information. Therefore, these use-cases are evidences on this fact that building information is current for smart industries as well. Therefore, this study believes that the presented process model can provide smart industries openly access to the buildings information.

\section{CONCLUSION}

The buildings information integrated with live data is a valuable asset which can be beneficial to many smart industries. Although diverse technologies such as building information modelling have been developed to manage the building information, however, industry users still are not able to take advantage from the combination of this information with the live data. Moreover, this combination should be openly accessible needless of the skills to use specific professional environments like the BIM. Overcoming this challenge, this research presented a process model to collect and integrate and store the integrated buildings information with the live data in an open storage. The presented process model by this paper has been prepared to apply in a real project in collaboration with facility management industry. By going through the future steps to implement the presented process model, more details will be provided to the readers. 
ACKNOWLEDGMent

This work was supported by the Science Foundation Ireland grant "13/RC/2094" and co-funded under the European Regional Development Fund through the Southern \& Eastern Regional Operational Programme to Lero - the Irish Software Research Centre (www.lero.ie).

\section{REFERENCES}

[1] M. Ajam, M. Alshawi, and T. Mezher, "Augmented process model for e-tendering: Towards integrating object models with document management systems," Autom.Constr. Vol. 19, pp. 762-778, 2010. https://doi.org/10.1016/j.autcon.2010.04.001

[2] S. Asadi, S. Shams Amiri, and M. Mottahed, "On the Development of Multi-Linear Regression Analysis to Assess Energy Consumption in the Early Stages of Building Design," Energy and Buildings, Vol. 85, pp. 246-255, 2014. http://dx.doi.org/10.1016/j.enbuild.2014.07.096

[3] B. Becerik-Gerber, F. Jazizadeh, N. Li and G. Calis, "Application areas and data requirements for BIM-enabled facilities management," J. Constr. Eng. Manag. Vol. 138, pp. 431-442, 2011. 10.1061/ (ASCE)CO.1943-7862.0000433

[4] N. Gu, V. Singh, K. London, L. Brankovic, and C. Taylor, "Adopting building information modeling (BIM) as collaboration platform in the design industry, CAADRIA 2008: beyond computer-aided design," Proc. of the 13th Conference on Computer Aided Architectural Design Research in Asia, The Association for Computer Aided ArchitecturalDesign Research in Asia (CAADRIA), 2008.

[5] British Institute of Facilities Management, (2013). "Benchmarking: Effective Performance Management for FM," British Institute of Facilities Management, UK, 2013.

[6] A. Capozzoli, D. Grassi, and F. Causone, "Estimation models of heating energy consumption in schools for local authorities planning," Energy and Buildings, Vol. 105, pp. 302-313, 2015. https://doi.org/10.1016/j.enbuild.2015.07.024

[7] I. F. Cruz, and H. Xiao,(2009). Ontology Driven Data Integration in Heterogeneous Networks, Complex Systems in Knowledge-based Environments: Theory, Models and Applications, Springer, Heidelberg, 2013, pp. 75-98.

[8] A. D'Elia, L. Roffia, G. Zamagni,F. Vergari, P. Bellavista, A. Toninelli, and S. Mattarozzi, "Smart applications for the maintenance of large buildings: How to achieve ontology-based interoperability at the information level," In Computers and Communications (ISCC), IEEE Symposium , pp. 1077-1082, 2010. 10.1109/ISCC.2010.5546639

[9] C. Eastman, C. M. Eastman, P. Teicholz, R. Sacks, and K. Liston, BIM Handbook: A Guide to Building Information Modeling for Owners, Managers, Designers, Engineers and Contractors, John Wiley \& Sons, Hoboken, 2011. (ISBN: 978-0-470-54137-1).

[10] M. Kassem, G. Kelly, N. Dawood, M. Serginson, and S. Lockley, "BIM in facilities management applications: a case study of a large university complex," Built Environ. Project Asset Manag., Vol. 5, No. 3, pp. 261-277, 2015. 10.1108/BEPAM-02-2014-0011

[11] I. Korolija, Y. Zhang, L. Marjanovic-Halburd, and V. I. Hanby, "Regression models for predicting UK office building energy consumption from heating and cooling demands," Energy Build., Vol. 59, pp. 214-227, 2013. https://doi.org/10.1016/j.enbuild.2012.12.005

[12] Y. W. Lee, D. M. Strong, B. K. Kahn, and R. W. Wang, "AIMQ: a methodology for information quality assessment," Information \& Management, Vol. 40, No. 2, pp.133-146, 2002.

[13] R. Mikučionienè, V. Martinaitis, and E. Keras, "Evaluation of energy efficiency measures sustainability by decision tree method," Energy
Build., Vol. 76, pp. 64-71, 2014. https://doi.org/10.1016/j.enbuild. 2014.02.048

[14] S. Mohandes, A. Abdul Hamid, and H. Sadeghi, "Exploiting building information modeling throughout the whole lifecycle of construction projects,” J. Basic Appl. Sci. Res. Vol. 4, No. 9, pp. 16-27, 2014.

[15] I. Motawa, and A. Almarshad, "A knowledge-based BIM system for building maintenance," Automation in Construction, Vol. 29, pp. 173182, 2013. https://doi.org/10.1016/j.autcon.2012.09.008

[16] J. Nummelin, K. Sulankivi, M. Kiviniemi, and T. Koppinen, "Managing Building Information and client requirements in construction supply chain - contractor's view," in: Proceedings of the CIB W078-W102 joint conference, Sophia Antipolis, France, Oct. 2011.

[17] W. J. O'Brien, R. R. A. Issa, J. Hammer, M. S. Schmalz, J. Geunes, and S. X. Bai, "SEEK: Accomplishing enterprise information integration across heteregeneous sources," ITcon Vol. 7, pp. 101- 124, 2002.

[18] E. A. Pärn, D. J. Edwards, and M. C. P. Sing, "The building information modelling trajectory in facilities management: A review". Automation in Construction, Vol. 75, pp. 45-55, 2017. http://dx.doi.org/10.1016/j.autcon.2016.12.

[19] K. Peffers, T. Tuunanen, M. A. Rothenberger, and S. Chatterjee, "A Design Science research methodology for information systems research", Journal of Management Information Systems, Vol. 24, No. 3, pp. 45-77, 2007. http://dx.doi.org/10.2753/MIS07421222240302

[20] Z. Pourzolfaghar, and M. Helfert, "Investigating HCI Challenges for Designing Smart Environments. In International Conference on HCI in Business", Government and Organizations, pp. 79-90, July 2016. Springer International Publishing.

[21] Y. Rezgui, A. Zarli and C. J. Hopfe, "Editorial - Building information modeling applications challenges and future directions," ITcon 14, pp. 613-616, 2009.

[22] W. Shen, Q. Hao, H. Mak, J. Neelamkavil, H. Xie, J. Dickinson, R. Thomas, A. Pardasani, and H. Xue, "Systems integration and collaboration in architecture, engineering, construction, and facilities management: A review". Advanced Engineering Informatics, Vol. 24 No. 2, pp. 196-207, 2010. https://doi.org/10.1016/j.aei.2009.09.001

[23] R. Szewczyk, E. Osterweil, J. Polastre, M. Hamilton, A. Mainwaring, and D. Estrin, "Habitat monitoring with sensor networks," Communications of the ACM, Vol. 47 No. 6, pp. 34-40, 2004. doi: $10.1145 / 990680.990704$

[24] M. C. Tremblay, A. R. Hevner, and D. J. Berndt, "Focus groups for artifact refinement and evaluation in design research," In Communications of the Association for Information Systems 26, Article 27, Vol 6, No. 1, 2010.

[25] J. Venable, J. Pries-Heje, and R. Baskerville, A comprehensive framework for evaluation in design science research. In International Conference on Design Science Research in Information Systems, 2012, pp. 423-438. Springer Berlin Heidelberg.

[26] G. M. Winch, Managing Construction Projects: and information processing approach. Wiley-Blackwell, 2010.

[27] Z. Yu, F. Haghighat, B. C. M. Fung, and H. Yoshino, "A decision tree method for building energy demand modeling," Energy Build., Vol. 42, pp. 1637-1646, 2010. https://doi.org/10.1016/j.enbuild.2010.04. 006

[28] The Climate Group, "Enabling the low carbon economy in theinformation age", Smart 2020, M. Webb, The Climate Group, 2008.

[29] A. H. Buckman, M. Mayfield, and S. BM Beck, "What is a smart building?" Smart and Sustainable Built Environment Vol. 3, No. 2, pp.92-109, 2014. https://doi.org/10.1108/SASBE-01-2014-0003 